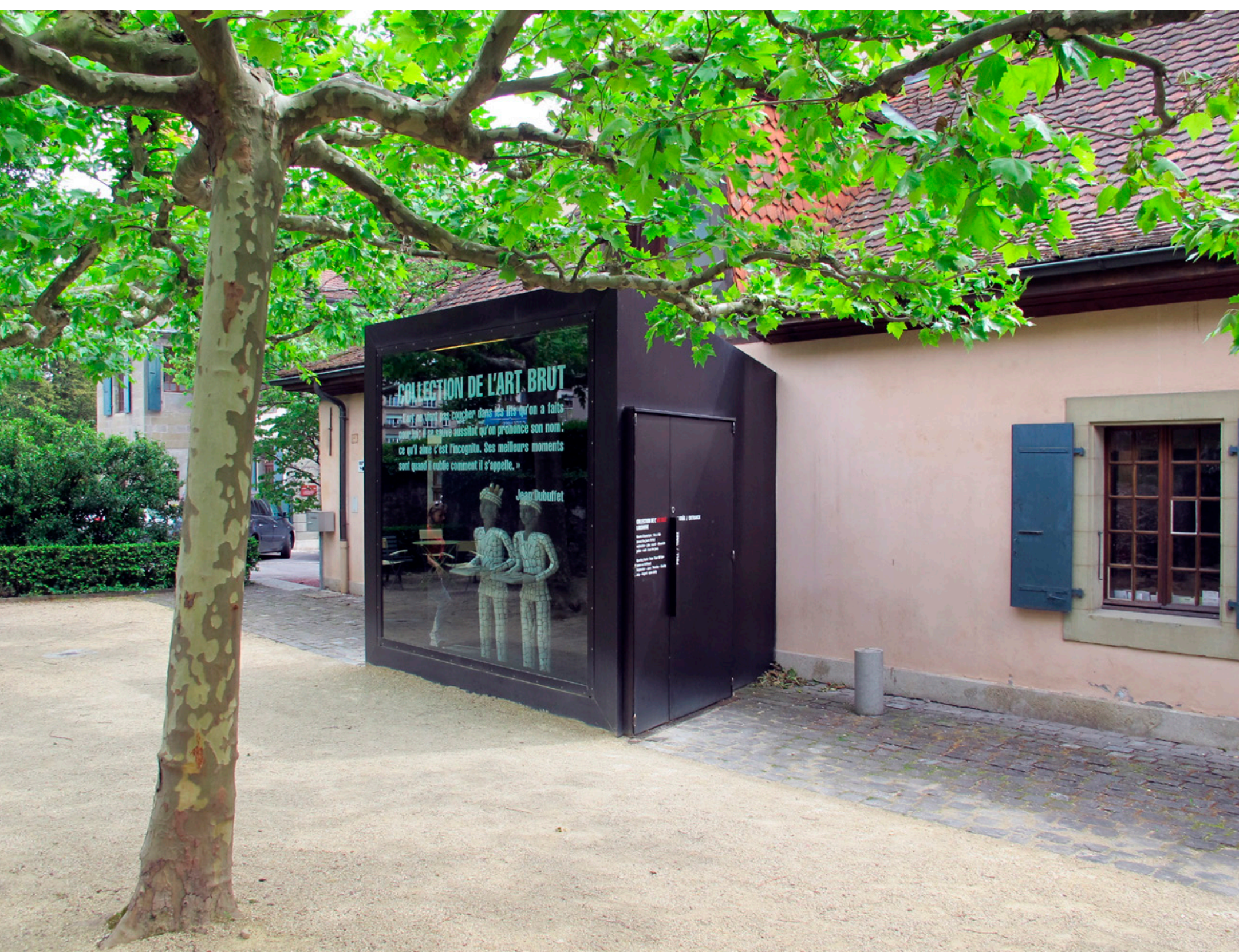

Vista de la fachada de la Collection de l'Art Brut en Lausanne. Fotografía: «Losanna, collection de l’art brut, 01» por Sailko bajo licencia CC BY 3.0. 


\section{DE LA CLANDESTINIDAD AL MUSEO: LA COLLECTION DE LART BRUT EN LAUSANNE}

\section{FROM SECRECY TO THE MUSEUM: THE COLLECTION DE L'ART BRUT IN LAUSANNE}

\section{Laura Pelayo González Doctora en Historia y Teoría del Arte Biblioteca y Centro de Documentación del MNCARS}

Resumen Este artículo se centra en la Collection de l'Art Brut en Lausanne, explorando su singularidad y el desarrollo de su colección. Además, se han introducido algunas experiencias previas del ámbito psiquiátrico que contextualizan esta propuesta, así como iniciativas coetáneas y posteriores al museo suizo que avisan de un aumento considerable en el número de entidades dedicadas al art brut y a otras prácticas artísticas afines.

Palabras clave

Abstract

Keywords
Collection de l'Art Brut, art brut, Jean Dubuffet, outsider art, arte marginal, arte singular.

This article focuses on the Collection de l'Art Brut in Lausanne exploring its uniqueness and the development of its collection. In addition, some previous experiences from the psychiatric field have been introduced to contextualize this proposal, as well as contemporary initiatives that came after the museum's foundation which bring attention to the considerable increase in the number of entities dedicated to art brut and other related artistic practices.

Collection de l'Art Brut, Art Brut, Jean Dubuffet, Outsider Art. 


\section{Un museo singular en Lausanne: la Collection de l'Art Brut}

El museo de la Collection de l'Art Brut se encuentra en Lausanne y surge a raíz de la donación que el artista Jean Dubuffet realizó a esta ciudad suiza en 1971. Se trata de la colección que el autor había ido seleccionando cuidadosamente a lo largo de su vida en torno al art brut $^{1}$. Este artículo pretende llamar la atención sobre las peculiaridades de este proyecto y contextualizarlo para ofrecer una panorámica más completa sobre la revalorización de estas prácticas artísticas y su creciente musealización. Así, en las páginas siguientes, se expondrá primero qué es el art brut y cuáles fueron algunas de las experiencias previas dedicadas a su conservación, difusión y estudio; a continuación, se profundizará en la colección desarrollada por Jean Dubuffet, atendiendo también al museo de Lausanne; $y$, finalmente, se presentará una visión general que refleje el aumento progresivo de este tipo de centros, un análisis que, sin ser exhaustivo, servirá para subrayar algunas cuestiones fundamentales que se retomarán a modo de conclusión.

\section{¿Qué es el art brut?}

El término art brut fue acuñado por Jean Dubuffet (Le Havre, 1901-París, 1985) en 1945 cuando, a raíz de su viaje por diversos hospitales psiquiátricos suizos, conoció la obra singular de algunos individuos considerados enfermos mentales. Dentro de esta expresión, englobó las producciones de estos pacientes, así como las de los médiums, prisioneros y otras personas sin formación artística, siempre que cumplieran dos requisitos: no pertenecer a los circuitos comerciales y desarrollar obras que destacasen por su espontaneidad, es decir, por su novedad respecto de la norma del

\footnotetext{
1 A lo largo de este texto se opta por emplear el término art brut en francés, en lugar de su traducción al español de "arte bruto", que podría llevar a confusiones y equívocos.
}

momento. Como se verá, estas últimas matizaciones, altamente condicionadas y subjetivas, marcarán el desarrollo de las teorías de este autor, las reestructuraciones de su colección y el museo de Lausanne.

En L'art brut préféré aux arts culturels, Dubuffet propuso esta definición de las creaciones brut:

Obras ejecutadas por personas indemnes de cultura artística, en las cuales el mimetismo, contrariamente a lo que ocurre en los intelectuales, tenga poco o nada que ver, de manera que sus autores lo extraen todo (temas, elección de materiales usados, medios de transposición, ritmos, formas de escrituras, etc.) de su propio fondo y no de los tópicos del arte clásico o del arte de moda. Asistimos en él a la operación artística totalmente pura, bruta, reinventada por completo en todas sus fases por su autor, a partir únicamente de sus impulsos. Se trata del arte, pues, donde se manifiesta la única función de la invención, y no aquellas, constantes en el arte cultural del camaleón o del mono (1973: 91-92)².

Como se aprecia en estas líneas, la creación del ámbito de lo brut llevó aparejada, por parte de Dubuffet, una crítica implacable hacia el arte contemporáneo, lo oficial y lo aprendido. Estos ataques se combinaron con una defensa enérgica de la libertad creativa que creía propia de algunos individuos pertenecientes a ciertos colectivos marginados, en los que las injerencias y los condicionantes de la sociedad y del mercado artístico habrían tenido un menor efecto.

Se trataba, por lo tanto, de una definición personal donde Dubuffet decidía qué artistas concretos podían enmarcarse dentro de este término. Este dirigismo del artista francés contribuyó a que, con el tiempo, otros coleccionistas y especialistas prefirieran emplear nomenclaturas nuevas, acordes a lo brut, pero menos restrictivas. Es el caso de la expresión outsider art, muy extendida en el ámbito anglosajón (Cardinal, 1972), y

2 Todas las traducciones del francés y del inglés que aparecen en este artículo han sido realizadas por su autora. 
de las acepciones más libres de arte singular, visionario o marginal.

Además de la importancia de Jean Dubuffet en la concepción y teorización del art brut, fue fundamental su esfuerzo por conservar y difundir unas obras que, generalmente, eran subestimadasy desechadas. Por aquel entonces, las escasas colecciones existentes procedían en su mayoría de instituciones mentales y habían surgido como intentos puntuales de algunos médicos de archivar las producciones de sus pacientes $^{3}$. Estas iniciativas funcionaron como antecedentes de la Collection de l'Art Brut y despertaron el interés de Dubuffet por este ámbito, quien, además, adquirió algunos de sus fondos ${ }^{4}$.

\section{Los antecedentes de la Collection de l'Art Brut: el arte de los locos}

Las primeras colecciones de lo que se denominó posteriormente art brut surgieron a finales del siglo XIX y principios del siglo $\mathrm{Xx}$ en algunas instituciones mentales europeas. Se trataba de recopilaciones puntuales de algunas producciones de los internos que eran empleadas como pruebas de las enfermedades que se creía que estos sufrían. Los casos documentados de conservación de estos conjuntos fueron una excepción en unas décadas en las que, en líneas generales, ni se alentaba la práctica artística de los pacientes-reclusos ni, de producirse, se guardaba o protegía. Asimismo, es importante

3 Como se verá más adelante en este texto, algunos representantes del surrealismo y del expresionismo alemán supieron de la existencia de estas creaciones a través de las publicaciones de algunos doctores. 4 De forma más general, la labor de Jean Dubuffet, en cuanto al estudio y la revalorización de la alteridad, se podría remontar al Romanticismo y a su atención por la locura y por la infancia. Un interés que recorrió el siglo xIx hasta alcanzar a las vanguardias históricas desarrollándose entonces también una especial admiración por las creaciones de otros pueblos y culturas, por el arte naï y por el arte popular.

Con el ánimo de no dilatar en exceso esta contextualización, el apartado siguiente se centrará en la conservación y en el estudio de las creaciones artísticas realizadas por aquellas personas consideradas enfermas mentales. Existen otros ámbitos afines al art brut, como pueden ser el arte infantil, el arte de otros pueblos y culturas, el arte popular o el arte naïf, que ejercieron una influencia notable sobre él, pero cuyo análisis excedería las pretensiones de este estudio. considerar que la emergencia paulatina de este ámbito de interés -que tildaron de arte de los locos- englobaba a individuos de sintomatología muy variada que podían padecer o no una patología. Estas personas habían sido encerradas y condenadas, generalmente de por vida, en función de una demencia que sus familiares, sus vecinos o las autoridades habían observado y sentenciado.

El doctor Auguste Marie, director del asilo de Villejuif en Francia, fue uno de los primeros en dedicarse al estudio y a la conservación de las creaciones realizadas por sus pacientes. En 1905 hizo pública la colección que había ido desarrollando y la abordó en su artículo Le Musée de la folie (El Museo de la locura), en la revista Je sais tout. Hay que considerar que este texto, en lugar de aparecer en la sección Arts et Lettres (Artes y letras), formó parte del apartado Curiosités (Curiosidades) (Morehead, 2011: 102). Esta clasificación avisaba de que estas prácticas no eran en absoluto identificadas como arte, sino como producciones extrañas, exóticas, más propias de un gabinete de curiosidades.

Dos años después de esta presentación del Musée de la folie, Paul Meunier, que ejercía también como doctor en Villejuif, publicó L'art chez les fous (El arte de los locos), una de las primeras ediciones dedicadas a este tipo de creaciones. Meunier, probablemente temeroso de las opiniones de sus compañeros de profesión, no sacó a la luz este libro bajo su rúbrica, sino que se ocultó tras el pseudónimo de Marcel Réja. Además, se cuidó de no emplear la expresión obra de arte, postulando que las perturbaciones psíquicas podían originar la aparición de una «actividad artística compleja» en la que el individuo se elevaba por encima de sus capacidades habituales, pero que en ningún caso conseguía igualar al artista académico. $\mathrm{Su}$ ensayo concluía asociando al loco con los niños, los salvajes y los prisioneros; grupos muy distintos y cuyas creaciones son tremendamente diversas, pero que han servido históricamente 


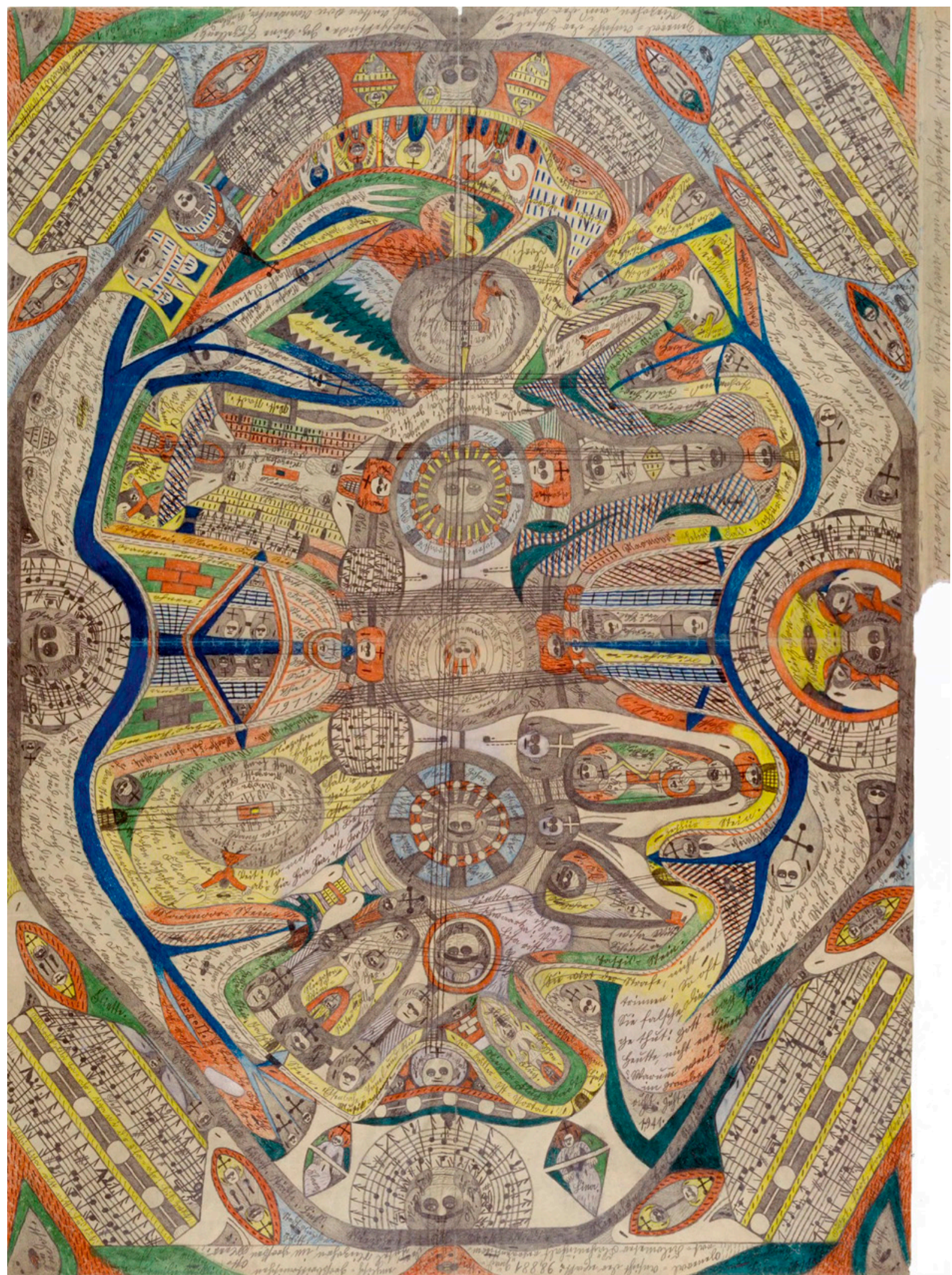

Adolf Wölfli, General view of the island Neveranger, 1911. Fotografía: «Adolf Wölfli General view of the island Neveranger, 1911» por Wiccan Quagga bajo licencia CC0 1.0. 
como constructos contrapuestos al hombre heterosexual blanco y sano que desde su discurso dominante los ha degradado e igualado.

Los trabajos de Meunier y de Marie en Villejuif dan indicios de un clima algo más propicio para la realización de este tipo de prácticas por parte de los internos, y de una mayor consideración de los especialistas que tomaron estas creaciones como objeto de estudio y conservación. Sin embargo, fueron aún casos aislados en los que, además, no existió una valoración artística como tal, sino, sobre todo, un interés clínico.

Una aproximación más novedosa en este sentido fue la del psiquiatra suizo Walter Morgenthaler, que publicó Ein Geisteskranker als Künstler: Adolf Wölfli (Un enfermo mental como artista: Adolf Wölfli) en 1921. Esta monografía versaba sobre Adolf Wölfli (Berna, 1864-Berna, 1930), internado en la clínica de Waldau (Berna) desde finales del siglo xix. La práctica artística de Wölfli destacó por su monumentalidad. Durante su encierro gestó una autografía de cuarenta y cinco volúmenes, compuesta de unas veinticinco mil hojas repletas de dibujos y collages. El doctor Morgenthaler, testigo de esta labor minuciosa y constante, decidió consagrarle un estudio en cuyo título empleaba el término artista como signo de su reconocimiento y consideración.

Walter Morgenthaler también tuvo un papel fundamental en la conservación del arte de los enfermos mentales en Suiza. El Hospital psiquiátrico de Waldau albergaba la colección de la Sociedad Suiza de Psiquiatría, formada con las creaciones de algunos internos. Morgenthaler se implicó en el desarrollo de este conjunto y consiguió que otras instituciones psiquiátricas depositaran en Waldau este tipo de producciones. De esta manera fue conformando en Berna un pequeño museo, accesible solo a unos pocos especialistas, cuyo funcionamiento $y$ presentación recordaban a una especie de gabinete de curiosidades ${ }^{5}$. El proyecto impulsado por Morgenthaler siguió desarrollándose a lo largo del siglo $\mathrm{xx}$ hasta constituirse como Psychiatrie Museum, actualmente dentro del circuito de los museos de la ciudad suiza.

El trabajo de Morgenthaler puede ponerse en paralelo con el del psiquiatra e historiador del arte alemán Hans Prinzhorn. En 1922, un año después de que la monografía de Wölfli saliera a la luz, Prinzhorn publicó Bildnerei der Geisteskranken: Ein Beitrag zur Psychologie und Psychopatologie der Gestaltung (traducida al español en 2012 como Expresiones de la locura. El arte de los enfermos mentales). Esta investigación analizaba con detenimiento las obras de los pacientes y establecía una clasificación de las mismas basándose en la identificación de una serie de pulsiones fundamentales. Bildnerei der Geisteskranken incluyó un gran número de imágenes y tuvo una influencia notable entre algunos artistas de las vanguardias históricas, como Paul Klee o Max Ernst, para quienes estas composiciones constituyeron una referencia y una fuente de inspiración (Cardinal, 1993: 104-107).

De forma similar a Morgenthaler, Prinzhorn no solo contribuyó a la revalorización del arte de los enfermos mentales con la publicación de su estudio, sino que, además, se implicó en el desarrollo de la colección del hospital donde trabajaba, en su caso, la Clínica psiquiátrica de Heildeberg. No obstante, cuando dejó de trabajar en esta institución, la iniciativa quedó paralizada y la mayor parte del conjunto permaneció acumulado en cajas, sin un control efecti$v^{6}$. Más adelante, Rave Schwank retomó el proyecto y, en la actualidad, Prinzhorn Collection

5 El museo también recogía otra documentación valiosa de sus archivos y ciertos materiales empleados habitualmente en las clínicas como, por ejemplo, camisas de fuerza.

6 Parte de sus fondos fueron exhibidos en «Entarte Kunst» (Arte degenerado) (1937), una muestra donde el nazismo puso en paralelo las obras de vanguardia con las creaciones de enfermos mentales resaltando así el declive que creían que se había producido en parte del arte occidental (Barron, 1991). 


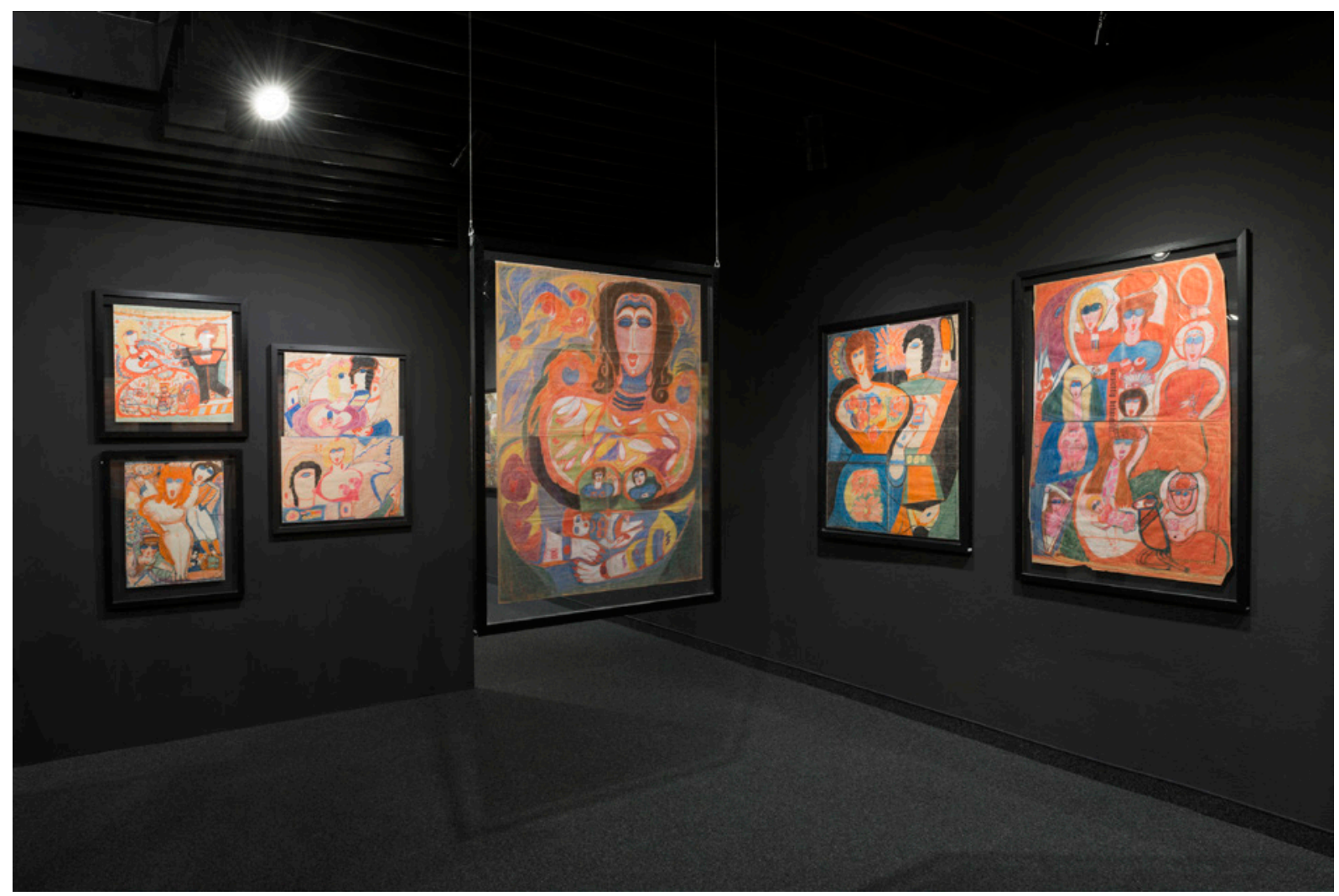

Vista interior de la Collection de l’Art Brut, Lausanne, en la que se puede apreciar la obra de Alö̈se Corbaz. Fotografía: Caroline Smyrliadis, Atelier de numérisation - Ville de Lausanne. Archives de la Collection de l'Art Brut, Lausanne.

conserva alrededor de seis mil obras realizadas desde mediados del siglo xix hasta 1940 por pacientes de diversas instituciones psiquiátricas.

Los esfuerzos de Prinzhorn y Morgenthaler fueron fundamentales para poner en valor el trabajo artístico presente en este tipo de creaciones. A pesar de que sus publicaciones $\mathrm{y}$ colecciones funcionaran aún como casos excepcionales, fueron la base de la que partió Jean Dubuffet que, al no ser un profesional de la psiquiatría, abordó estos autores y sus prácticas desde una óptica diferente, tratándolos plenamente como artistas y obras de arte, sin buscar una explicación médica, e introduciéndolos en las salas de exposiciones y en el entramado editorial de la crítica y de la historia del arte ${ }^{7}$.

7 Otros ejemplos serían el doctor Charles Ladame en Suiza o el británico Edward Adamson, considerado uno de los fundadores de la arteterapia.

\section{Jean Dubuffet y su colección de art brut}

Hasta los años cuarenta la dedicación de Jean Dubuffet al arte había sido intermitente. En su juventud había acudido a la Académie Julian en París, pero solo durante un breve periodo de tiempo, ya que después había preferido alejarse de los círculos académicos y formarse de manera autónoma. En 1924 abandonó la pintura para consagrarse al negocio familiar de los vinos y, aunque realizó algún acercamiento anterior, no retomó su carrera como artista hasta 1942. Esta vuelta al arte discurrió en paralelo a sus primeros contactos con el arte marginal de los locos, los médiums y otros autodidactas. Presentó su primera exposición en la Galerie René Drouin en 1944 y, un año después, emprendió junto a Jean Paulhan su viaje iniciático por Suiza conociendo de primera mano el arte que se escondía en sus hospitales psiquiátricos. 
Esta incursión por diversas clínicas le sirvió para conocer las obras de algunas de las figuras más destacadas del art brut y núcleo de su colección: Aloïse Corbaz, Adolf Wölfi y Anton Müller. La finalidad de este primer viaje no era realizar adquisiciones, sino conocer estas prácticas, investigarlas y abordarlas en una publicación. No obstante, posteriormente, la desaparición y la clandestinidad a la que parecían avocadas estas creaciones, desatendidas por la historia del arte y por las instituciones artísticas, le llevaron a emprender esta tarea de recolección y conservación. Los contactos que estableció en 1945, mediados en parte por el escritor suizo Paul Budry, fueron fundamentales en el devenir de este proyecto.

En sus primeras reflexiones, Dubuffet vinculó el arte realizado en los psiquiátricos no solo con el de los médiums, los autodidactas y los prisioneros, sino también con el arte de otras culturas, el arte infantil y el arte popular. Sin embargo, esta noción inicial tan laxa del art brut fue después pulida en detrimento de estos últimos ámbitos que creía más cercanos a lo oficial y a la tradición. De esta manera, el arte popular, naïf, infantil y el realizado por otras culturas fueron excluidos de su colección principal. No obstante, siguió reconociendo en algunos de estos individuos y colectivos cierta singularidad, de modo que tejió en su discurso la posibilidad de un escalón intermedio, entre lo brut y lo cultural, que se materializó en una colección secundaria denominada Neuve Invention (Nueva Invención) (Thévoz, Roulin y Peiry, 1988) ${ }^{8}$. Estos cambios y variables en su concepción teórica se permeaban, por lo tanto, a la formación y a la estructuración de su colección, y el actual museo de Lausanne será heredero de estas divisiones y jerarquías.

8 Como se vio en la primera parte de este texto, Jean Dubuffet arremetía duramente contra el arte cultural que asociaba con lo aprendido, lo socialmente aceptado, lo valorado y lo fomentado. Ambas colecciones formaron parte de la donación de Jean Dubuffet a Lausanne y, aunque en secciones diferentes, todas se reúnen dentro del museo que lleva por nombre Collection de l'Art Brut. A lo largo de este texto, cuando hablamos de "colección de Dubuffet» nos referimos a ambas.
Otra reorientación importante de su pensamiento se produjo al extenderse el cuestionamiento de los conceptos de pureza y originalidad que Dubuffet asociaba a lo brut, haciéndose evidente la imposibilidad de escapar de esa cultura a la que el artista francés quería hacer frente. Finalmente, Dubuffet optó por presentar, en lugar de categorías estancos, dos polos opuestos, uno brut y otro cultural, de manera que las obras tendieran más a uno o a otro, pero sin ser posible zafarse completamente de la enculturación (Thévoz, Roulin y Peiry, 1988: 157). Esta visión posterior, más flexible, ha sido la continuada por sus seguidores, especialmente por Michel Thévoz, autor de la obra de referencia Art Brut (1975) y primer director del museo de Lausanne.

En cuanto a la instalación de la colección de Jean Dubuffet y a su devenir, su primer emplazamiento oficial fue el Foyer de l'art brut (Hogar del art brut) en el sótano de la galería René Drouin en París. Entre 1947 y 1948, este espacio acogió las obras de distintos autores y técnicas que se disponían sin ningún tipo de señalización. Ante el rápido crecimiento de los fondos, el editor Gaston Gallimard cedió un pabellón en la ciudad donde poder trasladarlos. Este nuevo emplazamiento se convirtió también en la sede de la recién constituida Compagnie de l'art brut, de la que formaron parte, entre otros, André Breton, Michel Tapié y Slavko Kopac, nombrado conservador jefe de la colección. La iniciativa se nutrió así de las aportaciones de nuevos compañeros, y las labores de búsqueda de nuevos artistas y de adquisición de obras se prolongaron durante los años siguientes.

Paralelamente, se sucedieron las exposiciones y las publicaciones que fomentaron el estudio y la difusión del art brut. No obstante, Dubuffet mantuvo una postura proteccionista respecto a la colección defendiendo que el Foyer debía permanecer en cierto secreto y penumbra, siendo visitado solo por unos po- 
cos amigos e interesados ${ }^{9}$. Esta presentación entroncaba con los orígenes clandestinos de estas obras, pero su motivación fundamental era el temor a su normalización: a que la crítica, las instituciones y la historia del arte acabaran engullendo estas creaciones y a sus autores dentro de su maquinaria cultural ${ }^{10}$.

Tras estos años de actividad, la colección pasó a un segundo plano en los intereses de Dubuffet. En 1951 la compañía se disolvió y los fondos fueron trasladados a la residencia de Alfonso Ossorio en Long Island (Estados Unidos) donde gozaron de escasa difusión. Tras este paréntesis, en 1962, se expusieron algunas piezas en la galería Daniel Cordier y, poco después, retornaron a Francia. Dubuffet había adquirido recientemente una propiedad en París y la convirtió en la ubicación temporal de estas obras, procediendo de una manera reservada al permitir solo algunos accesos puntuales. Durante este periodo, reactivó también la Compagnie de l'art brut emprendiendo de nuevo la búsqueda conjunta de adquisiciones por diferentes países del mundo.

En 1967 se organizó una importante exposición de la colección del art brut en el Musée des Arts Décoratifs de París. Esta incursión en el museo puede resultar paradójica, ya que Jean Dubuffet renegaba de esta institución, acusándola de tradicional y elitista, y la contraponía a las creaciones espontáneas y marginales que él valoraba. Sin embargo, en este momento, enfocó la muestra como un ataque y una provocación al sistema del arte. Una forma de cambiar y dinamitar la institución desde dentro. El desarrollo de esta línea de acción explica en parte su donación en 1971 a la ciudad de Lausanne y su consiguiente mu-

\footnotetext{
9 Algunos de sus visitantes fueron, además de psiquiatras y especialistas en medicina, Jean Cocteau, Claude Lévi-Strauss y Pierre Matisse. No obstante, esta actitud de Dubuffet no impidió que se celebrase en 1949 una gran exposición con sus fondos en la galería René Drouin.

10 Este temor y estas precauciones seguirán latentes en la musealización de la Collection de l'Art Brut y en otras propuestas similares tanto coetáneas como actuales.
}

sealización. Una cesión motivada también por el deseo de Dubuffet, que por aquel entonces rondaba los setenta años, de asegurar el futuro de este conjunto, considerando tanto su conservación y desarrollo, como su estudio y difusión.

\section{El museo de la Collection de l'Art Brut}

Ante el interés que empezó a mostrar Jean Dubuffet por donar su colección de art brut, varios Estados le presentaron sus propuestas. El Ministro de Cultura francés realizó un acercamiento en este sentido, ofreciendo el nuevo Centre Georges Pompidou como posible destino de las obras, pero la iniciativa resultó infructuosa (Peiry, 2006: 172). Finalmente, a través del conservador de arte suizo Michel Thévoz, inmerso en la preparación de su monografía sobre el art brut, Dubuffet entró en contacto con las instituciones helvéticas con las que acabaría formalizando esta donación. Un acuerdo que se produjo en gran parte gracias a la disposición mostrada por George-André Chevalla, quien se comprometió a tomar las medidas adecuadas para que el proyecto museológico y museográfico estuviera en consonancia con los deseos y las intenciones del autor francés.

Hay que destacar que estas piezas, cuya exhibición permanente al público había sido siempre rehusada, iban a presentarse ahora ante cualquier visitante. Aunque la palabra museo no formara parte del nombre de la entidad, se trataba de una musealización del conjunto y del art brut. Sin duda, esto refleja un cambio importante en el pensamiento de Jean Dubuffet: su proteccionismo cedía e inclinaba la balanza hacia el lado de la preservación y de la difusión. Ciertamente, imponía importantes cuestiones al proyecto que aseguraban la continuidad de sus ideas y postulados, armando a la entidad para intentar posicionarla como un elemento crítico y disonante respecto del panorama museal habitual, pero la recon- 


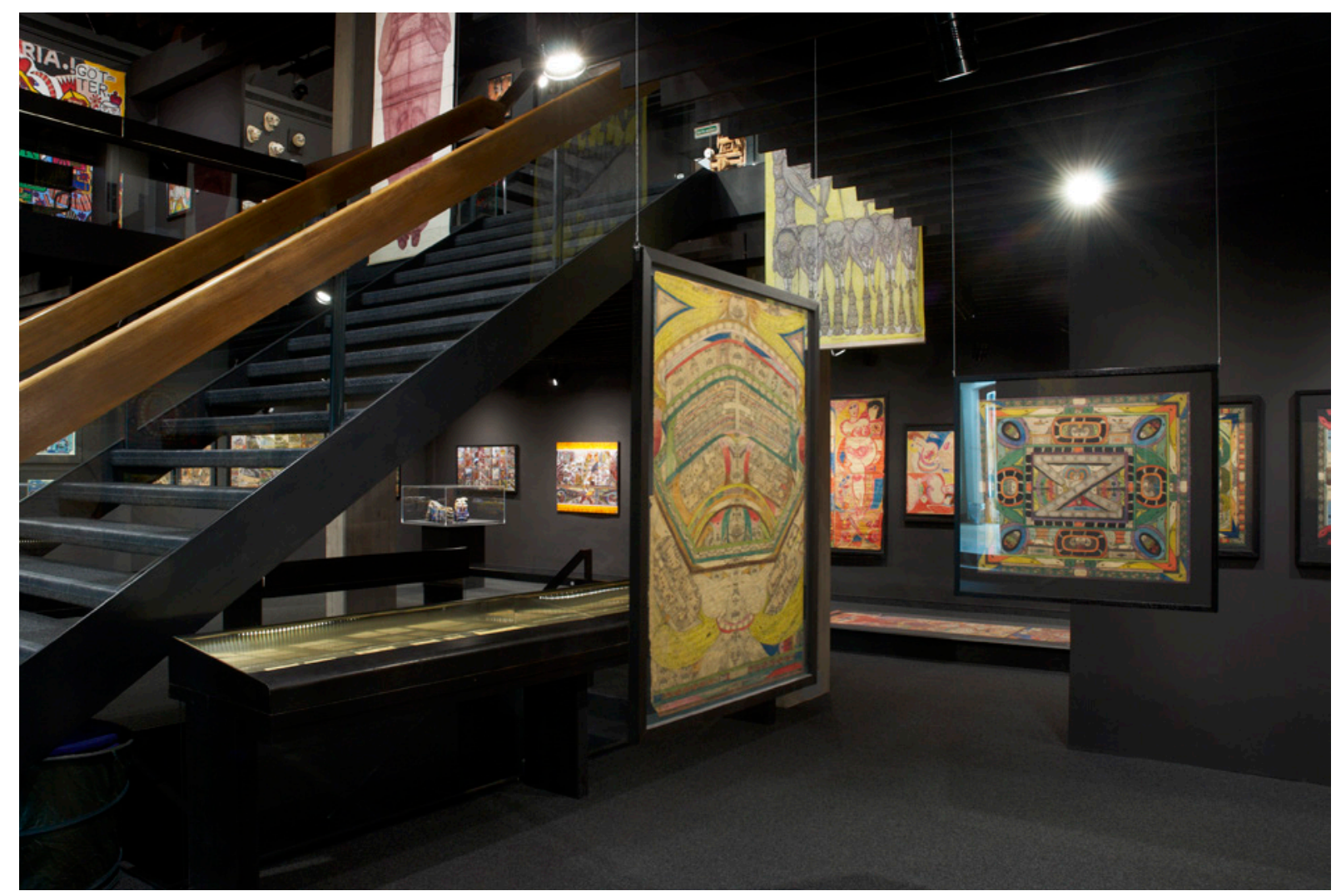

Vista interior de la Collection de l’Art Brut, Lausanne. En la zona central y en el lateral derecho, se pueden observar varias obras de Adolf Wölfli. Fotografía: Caroline Smyrliadis, Atelier de numérisation - Ville de Lausanne. Archives de la Collection de l'Art Brut, Lausanne.

sideración de parte de sus antiguas posturas al crearse este centro es evidente. Ahora, más que renegar de la institución o dinamitarla, se iniciaba un proceso de reinvención de la misma desde los márgenes.

En cuanto a la elección de la ciudad suiza, Dubuffet destacaba que no se trataba de una de las grandes capitales del arte y que, además, con este traslado, las colecciones regresaban a su origen: al país por el que realizó su viaje iniciático de 1945 y del que procedían buena parte de los fondos. La sede prevista era el castillo de Beaulieu, cuya construcción del siglo XVIII tuvo que ser restaurada y adaptada a las necesidades de la colección por los arquitectos Bernard Vouga y Jean de Martin ${ }^{11}$.

11 Posteriormente, ha sufrido diversas reformas (1983, 1985, 2002 y 2005), sobre todo, orientadas a ampliar el espacio expositivo y las zonas de trabajo interno.
En 1976 abrió sus puertas al público con un montaje expositivo que permeaba la singularidad de las obras y enraizaba con las connotaciones y los atributos otorgados al art brut. Se trataba de una sucesión de salas por diferentes pisos, marcados por una tenue iluminación y una rotunda pintura negra en las paredes. Una ambientación que pretendía recrear el espacio íntimo en el que estos trabajos se habían gestado.

Michel Thévoz ejerció como primer conservador jefe de la colección, formada inicialmente por unas cinco mil piezas ${ }^{12}$. Desde entonces, la -adquisición de obras ha sido constante, rondando en la actualidad las setenta mil e incluyendo nuevos autores que

12 Thévoz se encargó de la dirección del museo desde su apertura hasta 2001; a partir de entonces, le sustituyó en este puesto Luicienne Peiry y, desde 2011, Sarah Lombardi. 


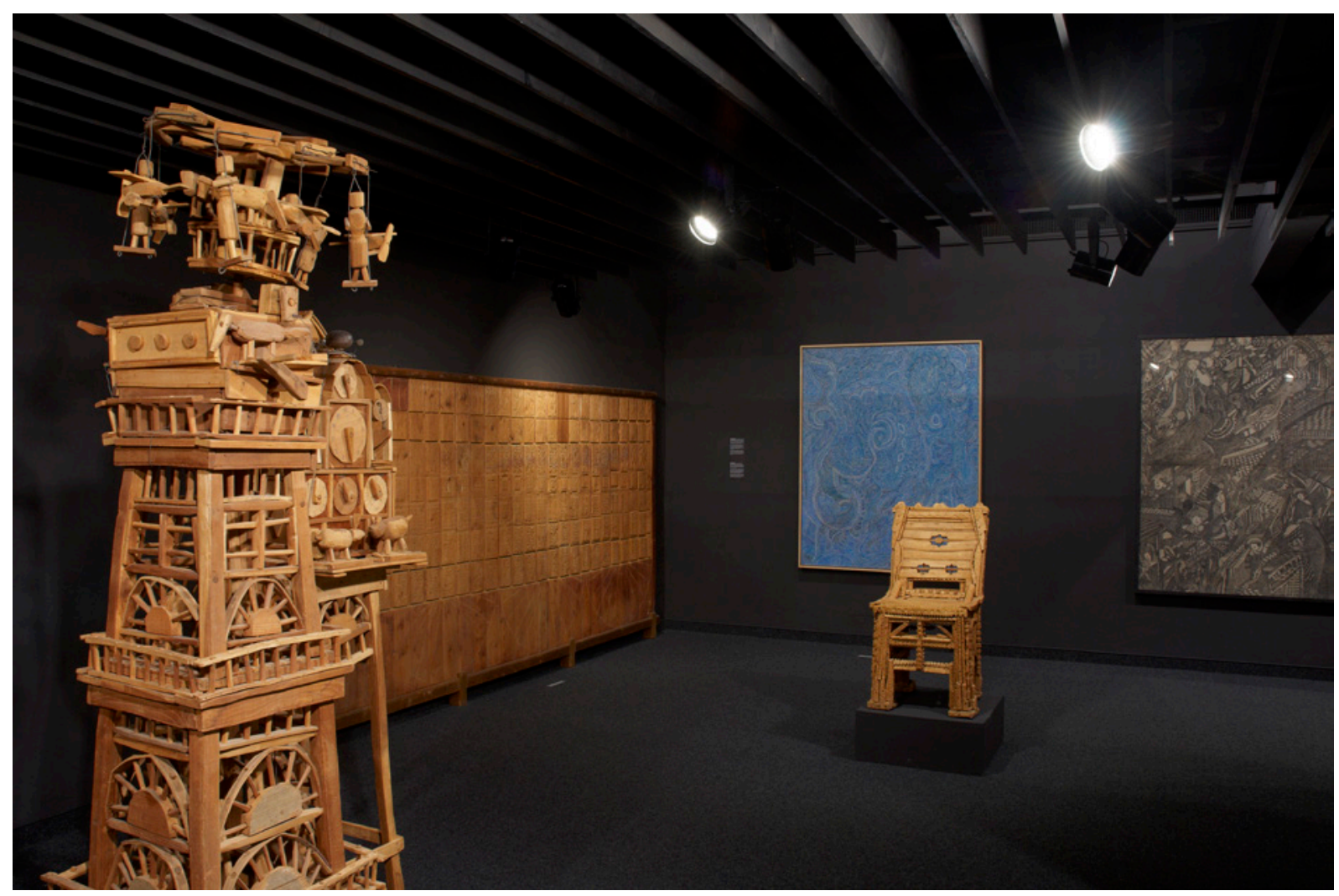

Vista interior de la Collection de l'Art Brut, Lausanne. Se pueden apreciar piezas de madera de Émile Ratier y Clément Fraisse. Fotografía: Caroline Smyrliadis, Atelier de numérisation - Ville de Lausanne. Archives de la Collection de l'Art Brut, Lausanne.

ya no han pasado el filtro de Jean Dubuffet. Es notable la variedad de prácticas artísticas que constituyen sus fondos, en los que tienen cabida las coloridas pinturas de Aloïse Corbaz, las muñecas de Morton Bartlett, las composiciones espiritistas de FleuryJoseph Crépin, las esculturas-bricolaje de Auguste Forestier, los monumentales diseños de Agustin Lesage, las composiciones con conchas de Pascal-Désir Maisonneuve o el vestido de novia de Marguerite Sirvins.

La institución es heredera de la clasificación de Jean Dubuffet que distinguía entre art brut y nueva invención -aquel escalón intermedio entre lo brut y lo cultural-. Por lo tanto, conserva una sección denominada Neuve Invention, donde se incluyen creaciones de Gaston Chaissac o Friedrich Schröder-Sonnenstern, que es definida como:
Un conjunto de obras subversivas e inventivas (pinturas, dibujos, esculturas, creaciones textiles) realizadas por artistas en una posición delicada respecto del medio cultural regulado por las galerías y los museos. Los autores de «Nueva Invención» se desmarcan de la creación homologada, principalmente a través de los procedimientos estilísticos que ponen en práctica, los materiales que emplean o sus audaces elecciones iconográficas (Collection de l'Art Brut, Lausanne, 2020).

Además de la colección permanente, las salas albergan exposiciones temporales que se han ido sucediendo desde su inauguración. Se trata de proyectos donde tienen cabida tanto creadores brut que han gozado de una mayor difusión y estudio (Madge Gill, Adolf Wölfli, etc.), como autores más recientes (Judith Scott, Guy Brunet) o de latitudes más alejadas, por ejemplo, en Art Brut du Japon, un autre regard 


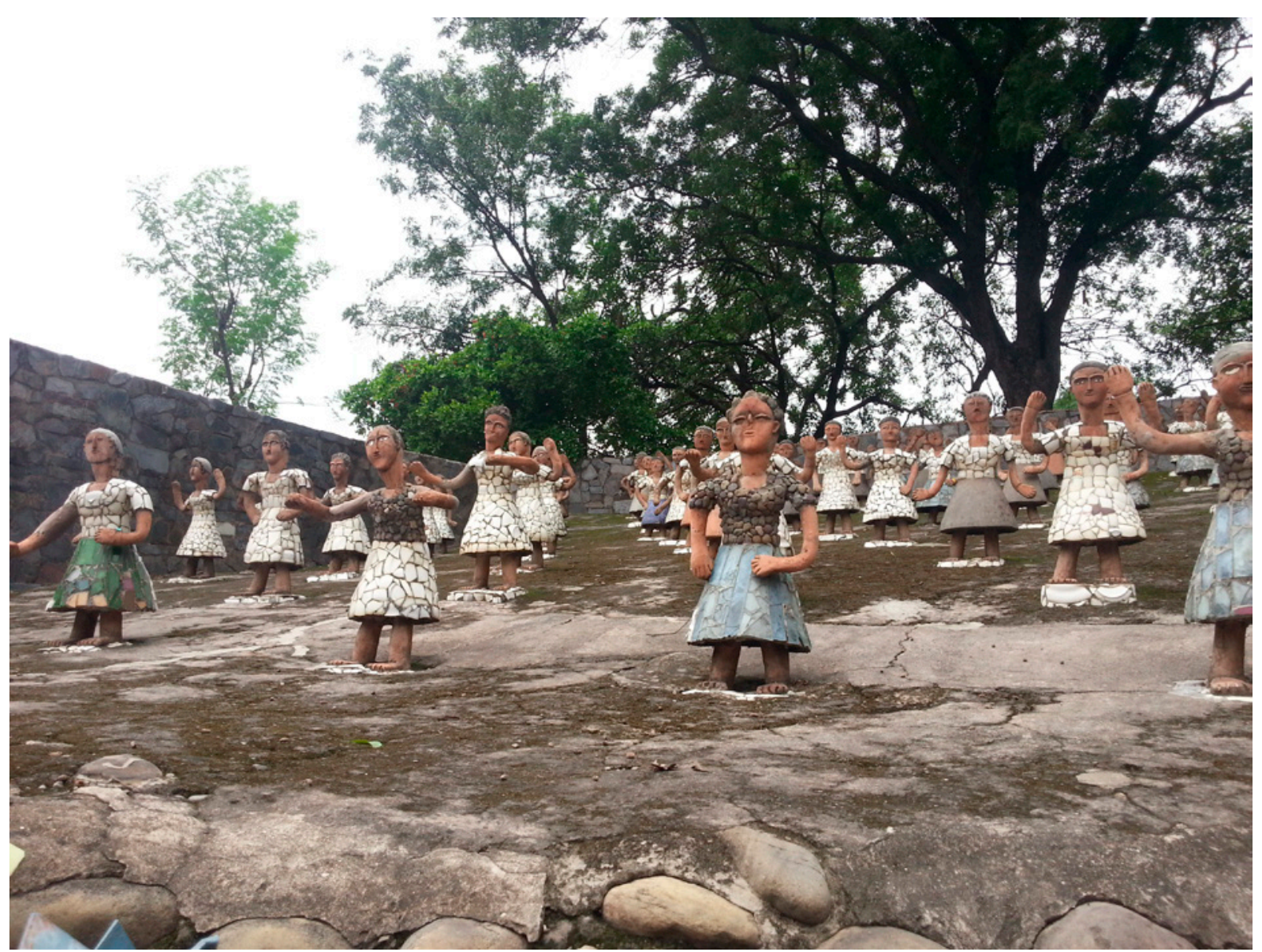

Imagen que muestra parte del Rock Garden de Nek Chand. Fotografía: «Chandigarh Rock Garden 34» por Ijon bajo licencia CC BY-SA 4.0.

(Art Brut desde Japón, otra mirada) (2018). Asimismo, se han ido tejiendo investigaciones colectivas alrededor de alguna tendencia o aspecto común, como Ecriture en délire (Escritura en delirio) (2004), y se ha procurado el diálogo con otros centros en la órbita de lo brut: Gugging (1984), Gugging: ouvres récentes (Gugging: obras recientes) (1990) y Creative Growth Art Center (2016) ${ }^{13}$.

Las exposiciones celebradas avisan también del interés creciente por las arquitecturas y los jardines de esculturas realizados por autodidactas y emparentados con lo brut. Así, entre no-

13 Desde noviembre de 2013, se realizan las Bienales del art brut, donde se explora la relación entre diversos artistas bruts y algún ámbito o referencia específico; en el caso de la edición de 2019, la temática central fué el teatro. viembre de 2005 y mayo de 2006, se pudo visitar «The Kingdom of Nek Chand» (El reino de Nek Chand), una muestra dedicada a este reconocido autor, artífice del Rock Garden en Chandigarh (India). Chand emprendió la construcción de este parque de esculturas de forma clandestina en 1958 y acabó consagrándose de por vida a esta labor, logrando que su jardín llegase a extenderse por ciento cincuenta mil metros cuadrados. También en esta línea arquitectónica-paisajística se programaron en la Collection de l'Art Brut: «Les bâtisseurs de l'imaginaire» (Los constructores de lo imaginario) (1976), «Richard Greaves, anarchitect» (Richard Greaves, anarquitecto) (2001), "Centenaire du Palais Idéal du Facteur Cheval» (Centenario del Palacio Ideal del Cartero Cheval) (2012) y «Art Brut XxL» (2019). 
La Collection de l'Art Brut logra atraer a casi cuarenta mil visitantes de media al año y cuenta con servicios y actividades propias de un museo: visitas guiadas, organización de conferencias, edición de catálogos y publicaciones especializadas, una librería, un centro de documentación, etc. ${ }^{14}$. No obstante, no ha perdido el carácter reivindicativo y disidente con el que Dubuffet vigorizaba el conjunto y sus responsables han seguido entendiéndolo y definiéndolo como una especie de «anti-museo» (Peiry, 2006: 177). En 1995, su director, Michel Thévoz afirmaba que:

Poner el Art Brut, es decir, el arte verdaderamente pobre, en el museo, recompensarlo además con los últimos perfeccionamientos técnicos de conservación y de seguridad, era una incongruencia, desde luego, un poco como introducir a un vagabundo en un palacio, pero una incongruencia provocadora que, bien lejos de 'recuperar' el Art Brut, volvía a poner el museo en crisis, haciendo reflexionar al visitante, es decir, al hombre del común, sobre las virtualidades antropológicas de la expresión a las que la enculturación le había llevado a renunciar (Thévoz, 1995: 67).

Este cariz subversivo, patente en las palabras de Thévoz, ha sido continuado por otras iniciativas, como La Fabuloserie. Sin embargo, esta línea de acción no ha sido la única, también se han efectuado otros tipos de recuperaciones que afrontan la difusión y la musealización de las creaciones en la órbita de lo brut desde otras perspectivas.

\section{Una panorámica sobre otras colecciones bruts $^{15}$}

Alain Bourbonnais había abierto el Atelier Jacob (Taller Jacob) en París, en 1972, enca-

14 Dentro de las actividades organizadas, se aprecia una atención especial hacia los públicos infantiles y juveniles que se pone de manifiesto en las visitas y talleres específicos, vertebrados por un énfasis en la creatividad y el sentido lúdico de la práctica artística.

15 Se han realizado algunos intentos de mapeo de este tipo de centros, aunque orientados a la guía de lectura útil y rápida (Maizels, 2009). minándose al coleccionismo del art hors-lesnormes (arte fuera de las normas) -un término acordado con Dubuffet ya que este último quería reservar el calificativo de brut para su propia colección-. Diez años después, cerró el taller e inauguró La Fabuloserie, un museo en la región de Dicy (Francia) realizado por él mismo. Este espacio cuenta con dos áreas diferenciadas: la casa-museo y el jardín habitado. El primero de ellos destaca por la extrañeza de su arquitectura, que genera una estructura laberíntica y fantástica. El segundo, posibilita la disposición de piezas escultóricas de gran tamaño creadas por habitants-paysagistes (habitantes paisajistas) para sus jardines ${ }^{16}$.

Como se mencionó al abordar las exposiciones temporales de la Collection de l'Art Brut, el ámbito de la arquitectura y de los jardines escultóricos en la órbita de lo brut es un campo de estudio que goza de un interés creciente. No obstante, por regla general, estos entornos no son exhibidos fuera de sus emplazamientos habituales al tratarse, no de obras individuales, sino de conjuntos cuyas piezas cobran sentido al presentarse juntas $y$ en la ubicación para la que fueron ideadas; además de que su tamaño, llegando a incluir la propia casa o áreas muy extensas, complican esta tarea. Sin embargo, aunque muchos de estos jardines y arquitecturas hayan sido convertidos en lugares de especial protección por las administraciones -el Palacio ideal de Ferdinand Cheval sería el mejor ejemplo de este tipo de reconocimiento-, la mayoría sufren un deterioro y expolio constante una vez que sus artífices fallecen. En este sentido, la labor de La Fabuloserie en la conservación y la difusión de este tipo de patrimonio es vital. Una tarea que parece también estar emprendiendo la Collection de l'Art Brut al haber incluido algunos trabajos de Nek Chand entre sus fondos.

16 Bajo la fórmula habitants-paysagistes, empleada habitualmente en el ámbito francófono, se engloban los jardines de esculturas realizados por autodidactas cuyas obras lindan con el bricolaje y la arquitectura (Lassus, 1975; Lassus, 1977). 
La Fabuloserie fue descrita por Jean Dubuffet como un anti-Beaubourg, enfrentándola así al Centre Georges Pompidou. Su catálogo reafirma esta actitud contestataria: el prólogo de Michel Ragon sostiene que estas creaciones son para sus artífices «una manifestación contracultural en relación a la civilización pequeño burguesa en la que la mayoría de ellos son obligados a ejercer sus actividades cotidianas», añadiendo que «están entre los escasos artistas en nuestra sociedad mercantilista que justifican todavía la función del arte» (Ragon, 1993: 21). Este autor subraya la gratuidad desde la que actúan estos artistas, mostrando un desinterés por lo comercial y por lo establecido, haciendo brotar sus obras de la motivación personal, pulsional, por crear.

Paralelamente a La Fabuloserie, en el contexto francés, han ido forjándose otras propuestas: el Musée de la Création Franche, en Bègles, que dentro de esta creación franca (honesta) incluye el art brut, el arte naïf y, de forma más general, el arte singular; la Galería abcd en Montreuil, surgida a partir de la colección de Bruno Decharme; Halle Saint Pierre, en París, que desde la exposición de 1995 "Art Brut et Compagnie, la face cachée de l'art contemporain» (Art brut y compañía la cara oculta del arte contemporáneo) ha albergado distintas muestras temporales en la órbita de lo brut, y la colección de L'Arcine, constituida en los años ochenta por Michel Nedjar, Madeleine Lommel y Claire Teller. Este último conjunto fue objeto de donación al Musée d'art moderne Lille Métropole en 1999.

Este museo, ahora denominado Lille Métropole Musée d'art moderne, d'art contemporain et d'art brut (LaM), articula desde una óptica nueva la inclusión de obras bruts en las instituciones. Otros centros de arte contemporáneo, a raíz del reconocimiento creciente de este tipo de producciones, han ido adquiriendo obras destacadas relacionadas con el art brut o el outsider art, como es el caso del MoMA, el Metropolitan Art Museum, el Cen- tre national d'art et de culture Georges-Pompidou o el Smithsonian American Art Museum. Mientras que LaM, no solo ha incorporado un importante fondo de art brut, sino que ha empleado este término como parte del nombre de la entidad, y ha propuesto un planteamiento diferente en el que estas creaciones dialogan $\mathrm{y}$ conviven en su exposición permanente con autores y movimientos reconocidos, promoviendo los acercamientos y las conexiones. Por lo tanto, lejos de construir un espacio cerrado y distante para lo brut, lo hace entrar de lleno en el contexto artístico contemporáneo situándolo en relativa igualdad de condiciones, desdibujando sus límites y categorías.

Prosiguiendo esta rápida panorámica, se hace evidente la proliferación, durante las últimas décadas, de centros dedicados a este tipo de arte por la mayoría de los países europeos: Art et Marges Museum en Bruselas, Moscow Mueum of Outsider Art, Museum of Naïve and Marginal Art en Jagodina (Servia), Safnasafnid (The Icelandic Folk and Outsider Art Museum, Islandia), Musgrave Kinley Outsider Collection (desde 2010 incluida en la Whitworth Art Gallery de Manchester), Kunsthaus Kannen en Munich, Museum im Lagerhaus de St. Gallen (Suiza) y Outsider Art Museum en Ámsterdam (vinculado al Hermitage), entre otros.

En este breve recorrido por el contexto europeo no se puede obviar el Art Brut Center Gugging. La colección de su museo parte de las experiencias llevadas a cabo en el Hospital psiquiátrico Maria Gugging, ubicado cerca de Viena, que desde los años ochenta ha potenciado la creación artística de sus pacientes al proporcionarles un espacio privilegiado donde alojarse y dedicarse de forma libre al arte, sin talleres ni horarios: la Haus der Künstler (Casa de los artistas). Su fachada fue decorada por sus artistas-habitantes y se contrapone a la imagen del resto del hospital. Hay que destacar que, dentro del ideario de Gugging, se aboga por que los autores exhiban sus obras 


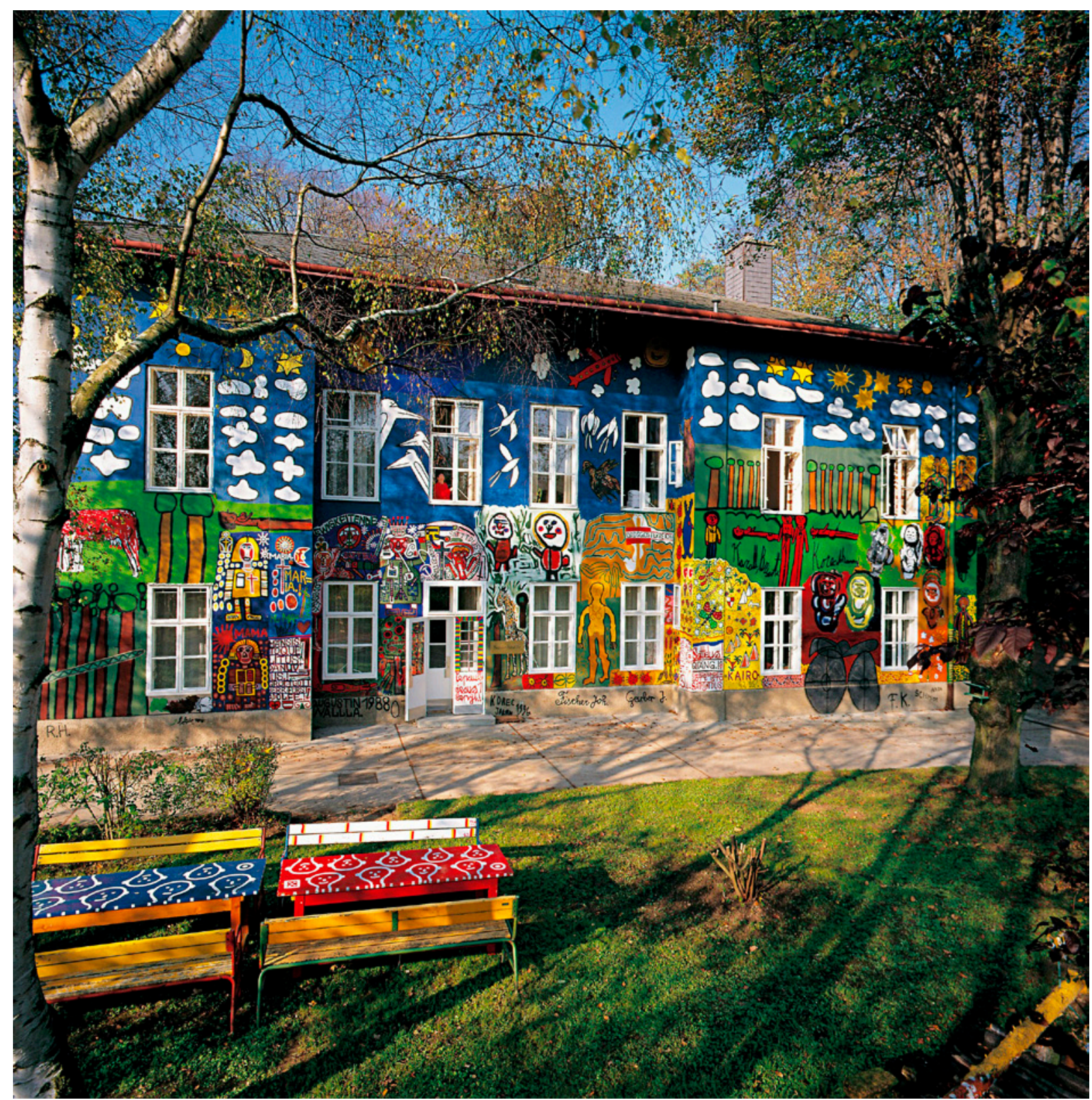

Fachada de la Haus der Künstler (Casa de los artistas) en Gugging. Fotografía: «Haus der Künstler Ostfassade» por Fundación privada - A rtistas de Gugging (Privatstiftung - Künstler aus Gugging) bajo licencia CC BY-SA 4.0.

y puedan venderlas y cobrar por ellas. Más recientemente, el centro ha incorporado el taller Gugging, un espacio abierto a cualquiera que desee explorar la práctica artística.

En cuanto a Estados Unidos, también en este país ha emergido una cantidad considerable de propuestas, sobre todo desde los años noventa, entre ellas: Intuit (The Center for Intuitive and Outsider Art), American Visionary Art
Museum y Grassroots Art Center. Además, otros museos dedicados al arte popular han ido incluyendo obras outsider, como es el caso del American Folk Art Museum de Nueva York, que cuenta desde 2001 con el Henry Darger Study Center. Asimismo, en la estela de Gugging, se encuentra el Creative Growth Art Center de Oakland, dedicado a personas con necesidades especiales a las que provee de 
un espacio donde poder dedicarse a la práctica artística, fomentando también su exposición y facilitando su venta.

Otros países y continentes también podrían incluirse en este itinerario por el mundo brut y outsider: Arts Project Australia, Museo Bispo do Rosario (Brasil), Borderless Art Museum NO-MA (Japón), etc. Por lo tanto, es evidente que, desde la apertura de la Collection de l'Art Brut en Lausanne, se ha producido un aumento considerable de centros dedicados a la conservación y a la difusión de obras afines a lo brut. Entidades entre las que se suelen urdir estrategias de cooperación comunes, reconociéndose como aliados disidentes. No obstante, sigue habiendo territorios en los que estas propuestas aún no han fraguado con determinación, por ejemplo, el caso español, donde la difusión de este tipo de obras se ha tenido que limitar a las exposiciones temporales, al ámbito editorial y a los artículos en publicaciones periódicas y páginas web ${ }^{17}$. Por lo tanto, aunque la operación puesta en marcha por Jean Dubuffet para sacar a la luz estas creaciones partió de un contexto terriblemente más aciago y precario, en la actualidad, una gran cantidad de conjuntos singulares se siguen encontrando en una clara situación de riesgo de desaparición. Asimismo, a pesar de que en varios países se aprecia una paulatina toma en consideración de estas prácticas, las iniciativas existentes, generalmente, no cuentan con los recursos ni con los apoyos adecuados para lograr la consecución efectiva de sus fines.

\section{Ante la musealización del art brut}

Guillermo Solana planteaba en 2006 una problemática que ha estado latente desde que

17 Algunas de estas exposiciones son: «Visiones paralelas: artistas modernos y arte marginal» (MNCARS, 1993), «La Colección Prinzhorn: trazos sobre el bloc mágico» (MACBA, 2001), «Art Brut: genio y delirio» (Círculo de Bellas Artes, 2006), «Mundos al descubierto» (Fundación La Caixa, 2006), «Jeanne Tripier: creación y delirio» (La Casa Encendida, 2018) y «El ojo eléctrico» (La Casa Encendida, 2019).
Jean Dubuffet iniciara su colección y a la que la musealización de estas prácticas artísticas ha de hacer frente:

Una cuestión que me inquieta es saber hasta qué punto este interés, surgido como decía a principios del siglo $\mathrm{xx}$, no distorsiona el fenómeno mismo del art brut. Es decir, el hecho de que observemos el art brut desde la tradición del arte instituido, ¿en qué medida lo transforma o incluso lo falsifica? (...) Es una paradoja recurrente: la historia del arte y las instituciones artísticas y culturales se sienten atraídas por esta otredad -que tan apropiadamente representa el art brut- pero, al mismo tiempo, con esa atracción corren el riesgo de hacer desaparecer el fenómeno o de distorsionarlo gravemente (Barja, Fauchereau y Solana, 2006: 81).

No se trata de una polémica nueva, es la misma que acontece a raíz del interés por las creaciones de sociedades tildadas de primitivas o cuando se produce la inclusión de ejemplos de notable ascendencia provocativa, incluso vandálica o callejera, en los centros de arte contemporáneo. Esta paradoja de la revalorización que, a la vez que favorece la conservación, el estudio y la reflexión, mitiga el efecto crítico, incluso subversivo, de ciertas obras, es un asunto clave y especialmente apreciable en el devenir de la colección de Jean Dubuffet.

El artista francés reflexionó sobre este punto y fue variando su postura de modo que, aunque reacio a la consagración oficial del art brut, acabó inclinándose del lado de la balanza en el que la supervivencia y el conocimiento de estas obras prevalecían. En las páginas de este artículo, se han visto algunas líneas de acción: la de la Collection de l'Art Brut y La Fabuloserie, optando por ejercer como contrapuntos, más distantes de los centros (sin que un alejamiento total sea posible); la de los espacios que, de forma más general y más apegados a la estructura del museo tradicional, se consagran a lo popular y a lo visionario como una oda a la creatividad de 
los seres humanos; la de los museos de arte contemporáneo en los que obras afines a lo brut comienzan a formar parte de sus fondos, o el caso de Lille Métropole Musée d'art moderne, d'art contemporain et d'art brut, marcado por una propuesta clara de acercamiento y diálogo.

Todas estas líneas de acción, por supuesto más complejas y difusas, y otras, algunas de las cuales se podrían atisbar con un análisis más exhaustivo, forman parte de esta panorámica cambiante en la que se reinventan la instituciones. La cuestión ya no es tanto derribarlas, como se desprendía de las insinuaciones iniciales de Dubuffet, sino imaginarlas y construirlas; poner en pie otros museos posibles y alterar y transmutar los existentes.

En el abanico de tácticas que se ha podido perfilar se hace patente cómo sus responsables han decidido, como finalmente hizo Dubuffet, no inclinar la balanza hacia el abismo de la desaparición y del descrédito. Muy al contrario, sus estrategias están determinadas a enriquecer el mapa de lo que entendemos por museo y por creación artística ya que un arte sin los otros, sin lo excluido y lo infravalorado, ofrece solo una mirada cíclope, medio ciega. No obstante, aunque estas tareas de inclusión puedan llegar a ser permanentes y siempre inconclusas, serán también reformulaciones encaminadas a desdibujar continuamente las fronteras, a construir entidades polimorfas, gabinetes y laboratorios para el tránsito y la reflexión crítica.

Por lo tanto, a pesar de los peligros que, de cara a la normalización y a la neutralización de su capacidad subversiva, suponga sacar a la luz y conservar estas obras, los proyectos que recorren estos caminos nos ayudan a conocer y a comprender mejor nuestros entornos pasados y presentes. Mientras que relegar al olvido y a la invisibilidad es una opción que lacera y distorsiona nuestra imagen de las prácticas artísticas, reinventar las instituciones y los centros de arte desde estos enfoques supone apostar por una panorámica más completa y compleja, más diversa y poliédrica.

\section{REFERENCIAS Y BIBLIOGRAFÍA}

Barja, Juan; Fauchereau, Serge y Guillermo Solana (2006) «Art brut, el arte como compulsión: coloquio Barja, Faucherau, Solana», Minerva: Revista del Círculo de Bellas Artes, 3: 81-85.

BARron, Stephanie (1991) «Degenerate Art» The Fate of the Avant-garde in Nazi Germany, Los Angeles: Los Angeles County Museum of Art.

Cardinal, Roger (1972) Outsider Art, London: Studio Vista.

- (1993) «El surrealismo y el paradigma del sujeto creador», en Tuchman, Maurice y Carol S. Eliel (eds.) (1993) Visiones paralelas: artistas modernos $y$ arte marginal, Madrid: Museo Nacional Centro de Arte Reina Sofía: 94-117.

Círculo de Bellas Artes (2006) Genio y delirio: Colección de art brut de Lausana, Madrid: Círculo de Bellas Artes.

Collection de l'Art Brut Lausanne (2020) Neuve Invention. Disponible en: https://www.artbrut.ch/ fr_CH/auteurs/neuve-invention [Fecha de consulta 24/08/2020]

Dubuffet, Jean (1967-1995) Prospectus et tous écrits suivants, Paris: Gallimard, 1-4.

- (1973) L’homme du commun à louvrage, Paris: Gallimard.

- (2004) Biografía a paso de carga, Madrid: Síntesis.

HeLler, Reinhold (1993) «Los antiguos del expresionismo», en Tuchman, Maurice y Carol S. Eliel, (eds.) (1993) Visiones paralelas: artistas modernos y arte marginal, Madrid: Museo Nacional Centro de Arte Reina Sofía: 78-93.

LAssus, Bernard (1975) Bernard Lassus: paysages quotidiens, de l'ambiance au démesurable, Paris: Etablissement public du Centre Beaubourg.

- (1977) Jardins imaginaires, Paris: Presses de la Connaissance. 


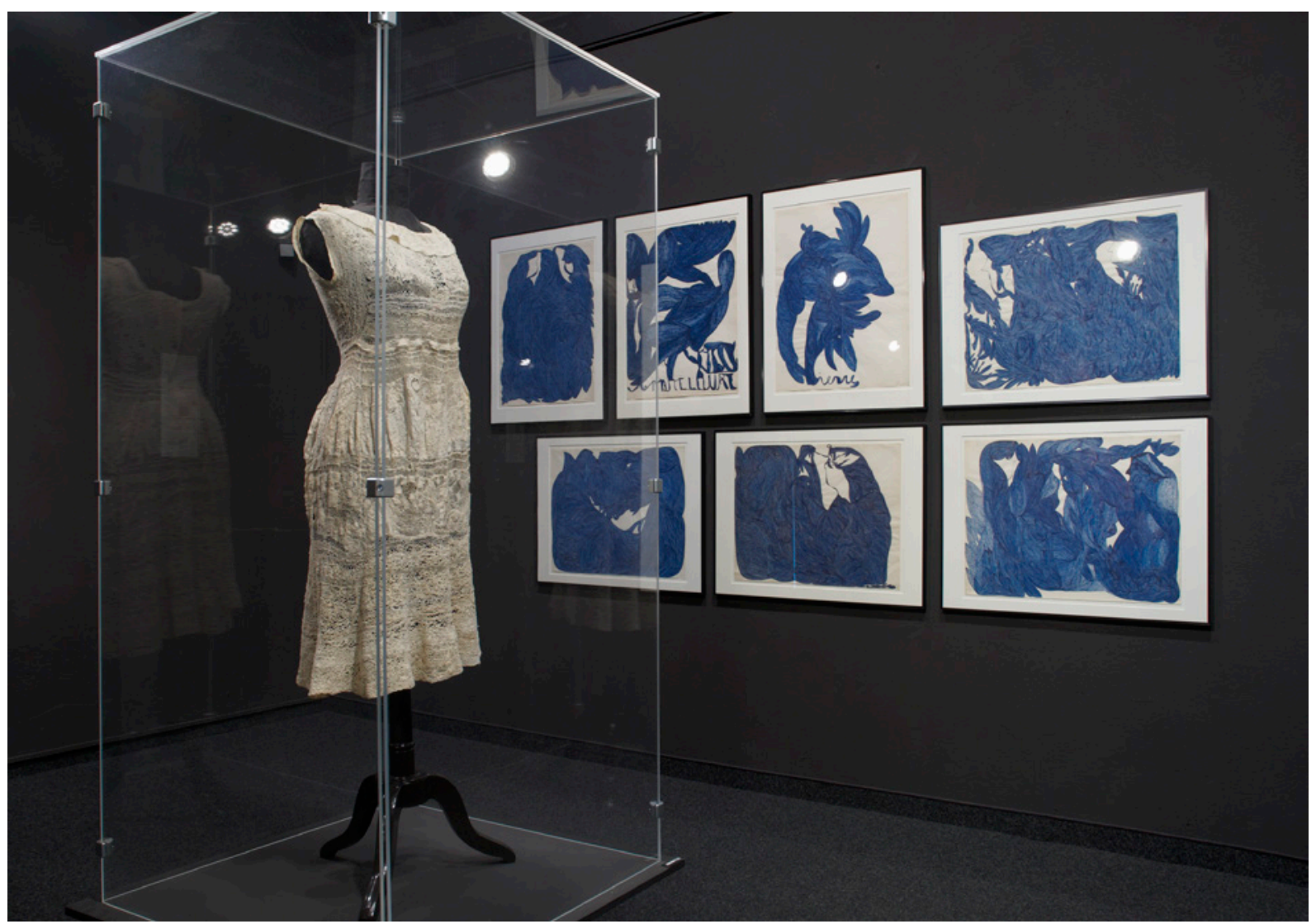

Vista interior de la Collection de l'Art Brut, Lausanne. Podemos ver el vestido de novia de Marguerite Sirvins y tintas de Laure Pigeon. Fotografía: Caroline Smyrliadis, Atelier de numérisation - Ville de Lausanne. Archives de la Collection de l'Art Brut, Lausanne.

Maizels, John (ed.) (2009) Outsider Art Sourcebook, London: Raw Vision.

MarIE, Auguste Armand (1905) «Le Musée de la folie», Je sais tout, 15 octobre, 9: 353-360.

Morehead, Allison (2011) «The Musée de la folie: collecting and exhibiting chez les fous», Journal of the History of Collections, 23, 1: 101-126.

Morgenthaler, Walter (1984) Madness and Art: The Life and Works of Adolf Wölfli, Lincoln: University Nebraska Press.

Peiry, Lucienne (2006) L’art brut, Paris: Flammarion.

Peiry, Lucienne (Dir.) (2012) Collection de l'Art Brut, Lausanne: Collection de l'Art Brut.

Prinzhorn, Hans (2012) Expresiones de la locura. El arte de los enfermos mentales, Madrid: Cátedra.

Ragon, Michel (1993) La Fabuloserie: Art hors les normes, Dicy: La Fabuloserie.

RÉJA, Marcel (2000) Lart chez les fous. Le dessin, la prose, la poésie, Paris: L’Harmattan.
Thévoz, Michel; Roulin, Geneviève y Lucienne PeIRY (1988) Neuve Invention: collection d'ouvres apparentées à l'art brut, Lausanne: Publications de la Collection de l'Art Brut.

ThÉvoz, Michel (1995) Requiem pour la folie, Paris: La Difference.

- (2001) Collection de l'Art Brut Lausanne, Zurich: Institut suisse pour létude de l'art-Genève.

Recibido el 14 del 9 de 2020

Aceptado el 3 del 11 de 2020

BIBLID [2530-1330 (2020): 56-73] 